\title{
Phagocytic Roles of Glial Cells in Healthy and Diseased Brains
}

\author{
Yeon-Joo Jung and Won-Suk Chung* \\ Department of Biological Sciences, Korea Advanced Institute of Science and Technology, Daejeon 34141, Republic of Korea
}

\begin{abstract}
Glial cells are receiving much attention since they have been recognized as important regulators of many aspects of brain function and disease. Recent evidence has revealed that two different glial cells, astrocytes and microglia, control synapse elimination under normal and pathological conditions via phagocytosis. Astrocytes use the MEGF10 and MERTK phagocytic pathways, and microglia use the classical complement pathway to recognize and eliminate unwanted synapses. Notably, glial phagocytosis also contributes to the clearance of disease-specific protein aggregates, such as $\beta$-amyloid, huntingtin, and $\alpha$-synuclein. Here we reivew recent findings showing that glial cells are active regulators in brain functions through phagocytosis and that changes in glial phagocytosis contribute to the pathogenesis of various neurodegenerative diseases. A better understanding of the cellular and molecular mechanisms of glial phagocytosis in healthy and diseased brains will greatly improve our current approach in treating these diseases.
\end{abstract}

Key Words: Phagocytosis, Astrocytes, Microglia, Synapse elimination, Neurodegenerative disease

\section{INTRODUCTION}

Glial cells are non-neuronal cells that are classified into three major cell types, astrocytes, oligodendrocytes, and microglia, which have different characteristics and functions in the central nervous system (CNS). Astrocytes play essential roles in the regulation of various brain functions. Astrocytes support neuronal survival and metabolism, control blood flow through vasodilation and vasoconstriction, and uptake neurotransmitters and ions at synaptic clefts (Araque et al., 1999, Sofroniew and Vinters, 2010; Hayakawa et al., 2016). Astrocytes also modulate synaptic formation, function and elimination at all stages of development and in adulthood (Allen and Barres, 2005; Stevens et al., 2007; Allen et al., 2012; Chung et al., 2013; Clarke and Barres, 2013; Lopez-Murcia et al., 2015; Lee et al., 2016; Yang et al., 2016a; Terni et al., 2017).

Phagocytosis is an essential element of the innate immune response, which functions as a defense mechanism against pathogens during infection and clearance mechanism for cellular debris produced during normal brain development and injuries (Fricker et al., 2012; Jones et al., 2013). Microglia in the CNS have been regarded as the only major phagocytes that mediate the elimination of synapses, apoptotic cells, neu- ral debris, and pathogenic proteins (Tahara et al., 2006; Jana et al., 2008; Meyer-Luehmann et al., 2008; Wang et al., 2015; Pomilio et al., 2016). However, It has been recently shown that astrocytes also have a strong phagocytic capacity and participate in the elimination of synapses and neuronal debris from the brain (Chung et al., 2013; Bellesi et al., 2017). Glial phagocytosis may be directly associated with the prevalence of various neurodegenerative diseases because defects in the phagocytic function of glial cells could result in the accumulation of unwanted elements in the brain with an abnormal immune response. This review discusses recent findings on the phagocytic roles of glial cells in the regulation of normal brain function and speculates on their potential roles in diseased brains.

\section{GLIAL CELLS ARE INVOLVED IN SYNAPSE ELIMI- NATION VIA PHAGOCYTOSIS}

Neurons generate excess synapses during development. These excess synapses subsequently undergo selective elimination to achieve precise neural connectivity (Allen et al., 2012; Clarke and Barres, 2013; Lee et al., 2016). Synapse elimination events also persist in the mature nervous system

\section{Open Access https://doi.org/10.4062/biomolther.2017.133}

This is an Open Access article distributed under the terms of the Creative Commons Attribution Non-Commercial License (http://creativecommons.org/licenses/by-nc/4.0/) which permits unrestricted non-commercial use, distribution, and reproduction in any medium, provided the original work is properly cited.
Received Jul 4, 2017 Revised Sep 12, 2017 Accepted Sep 26, 2017

Published Online Jan 10, 2018

\section{*Corresponding Author}

E-mail: wonsuk.chung@kaist.ac.kr

Tel: +82-42-350-2624, Fax: +82-42-350-5624 


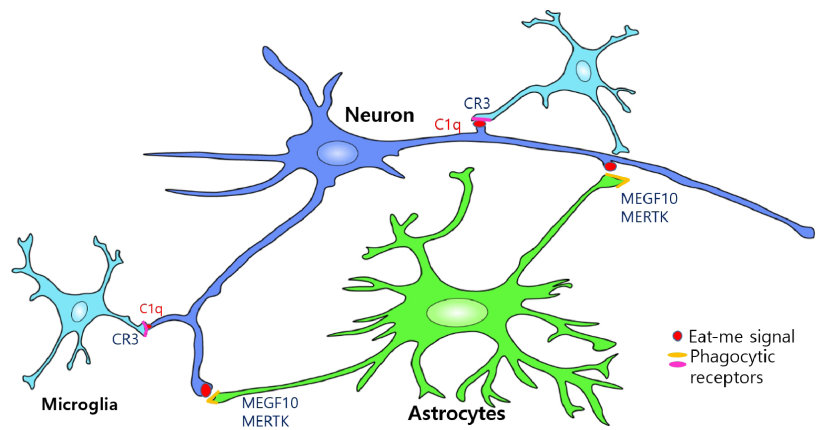

Fig. 1. Astrocytes and Microglia mediate synapse elimination by phagocytic pathways. Astrocytes (green) eliminate synapses from neurons (blue) by recognizing "eat-me" signals (red) presented in the unwanted synapses and phagocytosing them through MEGF10 and MERTK receptors (yellow). Astrocytes also mediate synapse elimination indirectly by inducing C1q expression in neurons (blue). C1qtagged synapses can be recognized and eliminated by complement component-3 receptor (C3R, magenta) in microglia (light blue).

via experience-dependent structural synaptic plasticity, but the number of elimination events may decline with age (Song et al., 2008; Chung and Barres, 2012; Lopez-Murcia et al., 2015; Cho et al., 2016; Lee et al., 2016; Terni et al., 2017). Therefore, synapse elimination is critical in the shaping of neural circuits during development and the regulation of synaptic plasticity in response to experience and memory. Certain neurodegenerative diseases, such as Alzheimer's disease (AD), are associated with profound synapse loss early in the disease state (Jana et al., 2008; Meyer-Luehmann et al., 2008; Pihlaja et al., 2008; Suh et al., 2013; Sollvander et al., 2016), which underscores the importance of understanding the molecular mechanisms of synapse loss.

The mechanisms of inappropriate synapse clearing during development are not known, but studies in mammals and flies have found that glial cells play central roles in this process. Glial cells are involved in all of the processes of developmental synapse elimination, including the proper recognition, engulfment, and degradation of synapses and neural debris (Allen and Barres, 2005; Chung and Barres, 2012; Diniz et al., 2014). Microglia in the mammalian CNS monitor and clear synapses during development via the complement pathway (Schafer et al., 2012). Our previous study demonstrated that astrocytes mediated synapse elimination via the MEGF10 (Multiple EGFLike Domains 10) and MERTK (Mer proto-oncogene Tyrosine Kinase) phagocytic pathways (Chung et al., 2013) (Fig. 1).

\section{MECHANISMS OF MICROGLIA-MEDIATED SYN- APSE ELIMINATION}

Microglia are derived from the hematopoietic lineage and express typical pattern recognition receptors. Microglial processes interact with presynaptic boutons and dendritic spines in normal brains, and direct contacts have been observed using electron and two-photon microscopy (Nimmerjahn et al., 2005). Each microglial cell surveys several synapses simultaneously and quickly changes its motility in response to extracellular stimuli.

Notably, microglia play critical roles in shaping the neural circuit connectivity of developing and normal brains. Microglia prune synaptic connections by engulfing pre- and postsynaptic elements in the hippocampus and retinogeniculate system during postnatal development (Paolicelli and Gross, 2011; Schafer et al., 2012).

Unwanted developing synapses in the retinogeniculate system are tagged with complement protein $\mathrm{C} 1 \mathrm{q}$, which is the initiating protein of the classical complement cascade (Stevens et al., 2007). The binding of C1q and opsonization of unwanted synapses trigger a protease cascade, which leads to the deposition of the downstream complement protein C3 (Gasque, 2004). Deposited C3 directly activate C3 receptors on microglia, which trigger elimination via microglial phagocytosis (Stevens et al., 2007) (Fig. 1).

The relevant complement proteins are normally downregulated by adulthood in the brain, but recent studies have revealed that $\mathrm{C} 1 \mathrm{q}$ is highly upregulated in aging brains (Stephan et al., 2013) and most neurodegenerative diseases (Hong et al., 2016), where it mediates abnormal synapse elimination (see the next section).

\section{MECHANISMS OF ASTROCYTE-MEDIATED SYN- APSE ELIMINATION}

Astrocytes are the most abundant cell type in the brain and constitute approximately $40 \%$ of brain cells. It has been estimated that one astrocyte ensheathes tens of thousands of synapses with its fine processes, which allows astrocytes to act as the first responders to any changes in synaptic activity, besides neurons. The fine astrocyte processes are highly dynamic and constantly modulate their association with synapses over the course of minutes. The degree of these dynamics are dependent on the physiological conditions. Notably, previous microarray studies of acutely isolated mouse brain astrocytes unexpectedly revealed that these cells express many components of evolutionarily conserved phagocytic pathways (Cahoy et al., 2008; Zhang et al., 2014). Two main pathways, the MEGF10 and MERTK pathways, were identified to begin serially but converge downstream in ways that remain poorly understood. Each pathway begins with a transmembrane signaling receptor that recognizes apoptotic cells via recognition of "eat-me" signals, such as phosphatidylserine (PS) in the outer leaflet of the target's plasma membrane or after the target has been coated by an opsonin. The first pathway includes MEGF10, which triggers the phagocytic process by engaging the intracellular protein GULP, engulfment adaptor PTB domain containing 1 (GULP1). ATP-binding cassette subfamily A member 1 (ABCA1: cholesterol efflux transporter) is also required, but the function of this protein in this pathway is poorly understood. Megf10 exhibits a high homology with draper in flies and ced-1 in worms, which play critical roles during phagocytosis of each organisms. The second phagocytic pathway is the MERTK pathway. MERTK works with the integrin pathway to regulate CRKII/DOCK180/Rac1 modules in controlling the rearrangement of the actin cytoskeleton upon phagocytosis. Several bridging molecules that recognize PS and interact with MERTK are GAS6, Protein S, and LGALS3, all of which are highly expressed and secreted by astrocytes.

Eliminating synapses via the MEGF10 and MERTK phagocytic pathways allows astrocytes to actively contribute to neural activity-dependent synapse pruning that mediates the 
refinement of neural circuits in the developing mouse brain (Chung et al., 2013). Retinal ganglion cells in developing mice deficient in the Megf10 and Mertk pathways exhibit failure in the normal refinement of connections and retain excess functional synapses with their primary targets, which are neurons in the dorsal lateral geniculate nucleus. This finding supports the active participation of astrocytes in the eliminating of live synapses rather than a simple removal of dead synaptic debris. Astrocytes also recognize and preferentially engulf weak synapses instead of strong synapses, and the presence of strong synapses is required to initiate this elimination process (Chung et al., 2013).

Microglia are traditionally thought to be the major glial cells that mediate synapse elimination, but astrocytes play a dominant role in eliminating synapses in the developing dorsal lateral geniculate nucleus. This role is partially due to the large number of astrocytes because astrocytes outnumber microglia 7 10-fold in developing brains. Astrocytes also continuously engulf excitatory and inhibitory synapses throughout the brain during adulthood, which suggests that astrocytes constantly remodel the synaptic architecture of our brains in response to our experiences.

\section{GLIAL CELLS IN AGING AND NEURODEGENERA- TIVE DISEASES}

Aging is the major risk factor for neurodegenerative diseases and cognitive decline. Synapse dynamics is the rate of synapse formation and elimination and is significantly altered by aging and changes in glial gene expression. Notably, C1q accumulates in aged brains approximately 300-fold greater compared to younger brains (Fraser et al., 2010; Depboylu et al., 2011; Stephan et al., 2013). This dramatic accumulation of C1q protein likely increases the vulnerability of brains to hyperactivation of the complement cascade, which can damage even healthy synapses via uncontrolled microglial phagocytosis. However, the triggers for the accumulation of $\mathrm{C} 1 \mathrm{q}$ protein and microglial hyperactivation in healthy aging brains are not known. Microglia exhibit increased immune responses, including phagocytosis, following various stimuli and aging, but astrocytes appear to lose their phagocytic capacity during reactive astrogliosis (Hong et al., 2016; Liddelow et al., 2017), which is a common feature of astrocytes in aging brains.

Drosophila glial cells in aged brains also lose their phagocytic capacity because of the decreased translation of draper, which is a homolog of Megf10 that astrocytes use for phagocytosing synapses (Tasdemir-Yilmaz and Freeman, 2014; Pearce et al., 2015; Purice et al., 2016). Restoration of the Draper levels rescue the phagocytic capacity of glial cells, which efficiently clear damaged axonal debris in aged brains to a similar extent as young brains. Taken together, these new findings suggest that aging may alter the phagocytic capacity of glial cells in the mammalian brain and lead to changes in brain and synaptic homeostasis, which may increase the vulnerability of aged brains to develop various neurodegenerative diseases.

\section{GLIAL CELL PHAGOCYTOSIS IN ALZHEIMER'S DISEASE (AD)}

The release of proinflammatory cytokines by reactive microglia and astrocytes surrounding $\beta$-amyloid $(A \beta)$ plaques is one of the leading factor in chronic inflammatory responses in AD (Salminen et al. 2009; McGeer and McGeer, 2013). This neuroinflammation plays a critical role in the pathogenesis of $A D$ via the induction of neuronal toxicity and cognitive decline (Akiyama et al., 2000; Lee et al., 2010). However, reactive gliosis may also be beneficial because reactive microglia and astrocytes are able to phagocytose and clear $A \beta$ deposits (Lee et al., 2010). Microglia mediate the clearance of $A \beta$ through receptor-mediated phagocytosis via the use of advance glycation end products (RAGE), toll-like receptors 2 (TLR2) and 4 (TLR4), scavenger receptor CD36, PS receptor and purine receptor P2Y6 (Noda and Suzumura, 2012; Jones et al., 2013). Microglial uptake of $A \beta$ and its subsequent targeting to the endosome-lysosome pathway were examined in detail using active microglia phagocytosing of monomeric, oligomeric and fibrillar $A \beta$ (Lee and Landreth, 2010). Ultrastructural studies also identified intra-cytoplasmic fragments of $A \beta$ in $A D$ microglia. Microglia are activated and recruited to $A \beta$ deposits in brains that contain neurons that overexpress amyloid precursor protein (APP) (Tahara et al., 2006; Bolmont et al., 2008; Meyer-Luehmann, et al., 2008). Microglia constitutively express TLR2 (Olson and Miller, 2004; Hanke and Kielian, 2011), and TLRs play a role in A $\beta$-induced microglial activation (Chen et al., 2006; Tahara et al., 2006; Tang et al., 2007; Liu et al., 2012). A $\beta$-triggered inflammatory activation is reduced in TLR2-deficient microglia (Jana et al., 2008; Suh et al., 2013), and TLR2 deficiency reduces $A \beta$-triggered inflammatory activation in cultured microglia, which suggests a beneficial effect of TLR2 inhibition in AD pathogenesis (Liu et al., 2012).

Triggering receptors expressed by myeloid cells (TREMs) are surface receptors on microglia, and TREM mutations confer a dramatically elevated risk for $A D$ and other neurodegenerative diseases (Cuyvers et al., 2014). Microglia highly express TREM2 (Painter et al., 2015), which is a key determinant of the CNS response to $A \beta$ accumulation (Zhang et al., 2013; Matarin et al., 2015; Slkoe and Hardy, 2016). Deletion of the TREM2 allele in human APP (hAPP) transgenic mice decreased the number of microglia associated with $A \beta$ deposits (Ulrich and Holtzman, 2016). Defective mTOR signaling in TREM2-deficient microglia is associated with a compensatory increase in autophagy in vitro and in vivo in AD models (UIland et al., 2017). TREM2 detects damage associated with lipids, which enables microglia to sense $A \beta$ accumulation and cell damage and supports microglia survival and $A \beta$-mediated reactive microgliosis (Wang et al., 2015). A recent study also described a novel microglia type associated with neurodegenerative disease (DAM) in AD model mice. Single cell analysis of DAM revealed that the DAM program was activated in a TREM2-independent and -dependent manner in the two-step activation processes, and disease-related gene expression changes were observed (Keren-Shaul et al., 2017).

$A D$ is associated with profound synapse loss early in the disease state. A recent study demonstrated reactivation of the complement pathway that is downregulated after initial synaptic pruning periods in AD brains and mediates abnormal synapse pruning via microglial cells (Hong et al., 2016). Functional suppression of $\mathrm{C} 1 \mathrm{q}$ prevents synapse loss during 
disease progression, which supports the microglial cell mediation of synapse loss in $A D$ brains. Reactive astrocytes also surround the sites of $A \beta$ deposits in human and animal $A D$ models and contribute to $A D$ pathophysiology via the release of proinflammatory cytokines and activation of microglia-mediated cytotoxicity (Jana et al., 2008; Park et al., 2008; Lee et al., 2010; Fu et al., 2014; Painter et al., 2015; Yang et al., 2016b). However, astrocytes are also competent phagocytes, and their ability to engulf $A \beta$ may be important in the identification of strategies to reduce $A \beta$ accumulation in $A D$ (Jones et al., 2013). Few studies have examined the phagocytic roles of astrocytes in $A \beta$ clearance, but a decrease in $A \beta$ levels was reported when astrocytes were added to brain sections prepared from a mouse model of AD (Wyss-coray et al., 2003). Astrocytes transplantations into the brains of transgenic $A D$ mouse models containing mutated APP and PSEN1 (PS1), APPswe/PS1dE9, were found near $A \beta$ deposit and internalized $A \beta$. Thus, astrocytes have a capacity of clearance of $A \beta$ (Pihlaja et al., 2008). In addition, astrocytic LRP-1 is reported to mediate $A \beta$ clearance and regulates $A \beta$ metabolism both in vitro and in vivo models (Liu et al., 2017).

The phagocytic roles of astrocytes may also be important in maintaining brain homeostasis. A recent study found that the strongest genetic risk factor for AD, APOE4, suppressed astrocyte-mediated phagocytosis (Chung et al., 2016). By contrast, the protective APOE allele for AD, APOE2, significantly enhanced the phagocytic capacity of astrocytes in vitro and in vivo. C1q protein accumulation, which may represent the amount of senescent synapses with increased vulnerability to complement-mediated degeneration, was also significantly reduced in APOE2 knock-in (KI) animals, and C1q accumulation was significantly increased in APOE4 $\mathrm{KI}$ animals in the 18-month-old mouse hippocampus. Astrocytes constantly engulf synapses in adult brains, and the decreased C1q accumulation in aged APOE2 $\mathrm{KI}$ animals supports the hypothesis that maintaining the synaptic environment devoid of senescent synapses prevents aberrant immune activation/inflammation and neurodegeneration. By contrast, a decrease in the overall phagocytic capacity of astrocytes may lead to the accumulation of senescent synapses and their debris, which may be at least partially responsible for the enhanced vulnerability of the brain to AD via hyperactivation of the complement pathway (Chung et al., 2016).

\section{GLIAL CELL PHAGOCYTOSIS IN HUNTINGTON'S DISEASE (HD)}

$\mathrm{HD}$ is an autosomal dominant inherited neurodegenerative disorder. Patients suffering from HD exhibit specific symptoms, such as random involuntary movements as well as psychiatric and cognitive impairment (Jiang et al., 2016; Jansen et al., 2017). These symptoms are highly associated with neuronal dysfunction in the striatum and other brain regions (Ghoshi and Tabriz, 2015). HD is caused by an expanded polyglutamine repeat localized to the $\mathrm{N}$-terminal region of the huntingtin protein, with intracellular accumulation and aggregation (Jiang et al., 2016). Astrocytes and microglia are activated in HD patients, as shown by GFAP and Iba1 upregulation (Jansen et al., 2016). Astrocytes with mutant huntingtin (mHTT) downregulate potassium channel Kir4.1, which leads to increased extracellular potassium concentrations and subsequent neu- ronal excitability (Tong et al., 2014; Sofroniew, 2015). The loss of the Kir4.1- and Glt-1 (Glutamate transporter 1)-mediated homeostatic functions of astrocytes cause defects in astrocytic glutamate and $\mathrm{Ca}^{2+}$ signaling, which contribute to the altered neuronal physiology in the striatum. Defects in the striatal circuit in HD patients are remedied by correcting key astrocyte homeostatic dysfunctions that precede overt astrogliosis and neurodegeneration (Jiang et al., 2016).

mHTT aggregation in drosophila neurons was transported to astrocytes via Draper. This phagocytic clearance of neuronal mHTT aggregation by glial cells may contribute to the spread of pathogenic protein aggregates in various neurodegenerative diseases (Pearce et al., 2015). Although there are a few studies reporting the presence of $\mathrm{MHTT}$ inclusions in astrocytes and oligodendrocytes (Shin et al., 2005; Tong et al., 2014; Huang et al., 2015; Jansen et al., 2016), precise molecular mechanisms of this phenomenon and its implications during the initation and progression of HD remain elusive.

\section{GLIAL PHAGOCYTOSIS IN PARKINSON'S DISEASE (PD)}

$\mathrm{PD}$ is a progressive neurological disorder that is characterized by the loss of dopaminergic neuron in substantia nigra pars compacta (SNpc), which results in tremor, bradykinesia, and muscle stiffness. $\alpha$-synuclein is a major component of the intracellular protein deposits, called Lewy bodies, in specific regions of the brain stem, spinal cord, and cortex (Park et al., 2008; Lees et al., 2009; Phatnani et al., 2015). Previous studies have demonstrated that $\alpha$-synuclein influenced microglia activation (Austin et al., 2006; Klegeris et al., 2008). Microglial cells treated with extracellular monomeric $\alpha$-synuclein exhibited increased phagocytic activity in vitro in time- and dosedependent manners (Park et al., 2008; Fu et al., 2014). By contrast, aggregated $\alpha$-synuclein inhibited the phagocytic capacity of microglial cells by antagonizing monomeric-facilitated clearance and decreasing the basal microglial phagocytic capability (Park et al., 2008; Fu et al., 2014). A recent study reported that astrocyte-derived GDNF regulated midbrain microglial activation and exhibited a neuroprotective effect via inhibition of the degeneration of dopaminergic neurons in the nigrostriatal system in PD animal models (Rocha et al., 2012). Previous studies also demonstrated that various microglial receptors, including the C1q-mediated clearance pathway (Depboylu et al., 2011) and scavenger receptor class B (Michaelakakis et al., 2012), were involved in the endocytosis of $\alpha$-synuclein. Several studies have demonstrated that microglia were more effective in endocytosing $\alpha$-synuclein compared to astrocytes and neurons (Rojanathammanee et al., 2011; Fu et al., 2014), but whether microglial uptake of $\alpha$-synuclein plays a beneficial or harmful response to the pathophysiology of PD is not clear.

\section{GLIAL PHAGOCYTOSIS IN MOTOR NEURON DISEASES}

Amyotrophic lateral sclerosis (ALS) is characterized by a progressive loss of motor neurons in the motor cortex, brainstem, and spinal cord (Hardiman et al., 2011; Radford, 2015). ALS exhibits rapid disease progression and leads to death 


\section{Glia Phagocytosis}

Normal condition
$\begin{aligned} & \text { Removal of unwanted } \\ & \text { synapses }\end{aligned}$
Removal of turn-overed
apoptotic cells
Removal of
membrane debris

Fig. 2. Two aspects of glial phagocytosis Astrocyte- and microgliamediated phagocytosis play various roles under different physiological conditions. In normal and healthy conditions, glial phagocytosis involves in regulation of neural circuit remodeling by eliminating unwanted synapses and neurites. Furthermore, glia mediates removal of apoptotic cells and neuronal debris in maintaining brain homeostasis. In pathological conditions, astrocytes and microglia phagocytose protein aggregates, such as A, Htt, and $\alpha$-Syn to clear accumulated proteins in the brains with neurodegenerative diseases. However, hyperactivation of glial phagocytosis can play deleterious roles by phagocytosing and eliminating intact synapses and stressed neurons, contributing to the initiation and progression of neurodegeneration and cognitive declines.

within 2-3 years of symptom onset (Lasiene and Yamanaka, 2011). Astrocytes and microglia are critical regulators via the removal of damaged motor neurons and mutant SOD1 in ALS pathology. Astrocytes become activated and release increased levels of cytokines in ALS, including TNF- $\alpha$, IFN- $\gamma$, and IL-1 $\beta$ (Philips and Robberecht, 2011). Astrocytic protein inclusions containing mSOD1 are an early feature of the disease in the mSOD1 mouse model. Selective expression of mSOD1 in astrocytes alone failed to provoke an ALS phenotype (Gong and Elliott, 2000), but the silencing of mSOD1 expression in astrocytes significantly slowed disease progression in the SOD1 ${ }^{\mathrm{G} 37 \mathrm{R}}$ mouse model (Yamanaka et al., 2008), without affecting the level of astrogliosis. Previous studies have demonstrated that normal motor neurons develop features of ALS pathology when surrounded by mSOD1-expressing glial cells in chimeric mice models (Clement et al., 2003). Benkler et al. (2013) demonstrated that the reduced glutamatergic response of astrocytes in SOD1 ${ }^{\mathrm{G} 93 \mathrm{~A}}$ mouse models may lead to disruption of glutamate homeostasis and accumulative CNS damage, which facilitate motor neuron degeneration.

Microglia are also a component of ALS pathology. Activated microglia are widely detected in the brains of living ALS patients using positron emission tomography (Turner et al., 2004; Lasiene and Yamakata, 2011). Activation of microglia results in the elevation of proinflammatory cytokines in mutant SOD1 mice. Mutant SOD1-expressing microglia release higher levels of TNF- $\alpha$ and IL-6 compared to wild-type microglia following LPS exposure (Weydt et al., 2004). Dysfunctional microglial phagocytosis is also related to ALS risk. Profilin 1 is a regulator of actin dynamics for phagocytosis (Kim et al., 2012; Radford et al., 2015). Profilin 1 mRNA expression level is upregulated in activated microglia, which leads to changes in cell morphology and phagocytic capacity (Dong et al., 2004). Mutations of profilin 1 were identified in familial ALS and are essential in the upregulation of the phagocytosis of microglia (Radford et al., 2015).

\section{CONCLUSIONS AND PERSPECTIVES}

We have described evidence that glial cells are active regulators in brain functions via phagocytosis. This evidence raises the intriguing possibility that the phagocytic activity of astrocytes and microglia regulate normal synaptic function and that changes in glial phagocytosis contribute to the pathogenesis of neurological disorders (Fig. 2).

Reactive gliosis and neuroinflammation were previously considered secondary events caused by the degeneration of neurons. However, recent findings demonstrated that microglia and astrocytes contributed to the initiation of neurodegenerative diseases, including AD, HD, PD and ALS. Astrocytes and microglia are closely associated with each other at the sites of pathogenic regions, and these two cell types may crosstalk and induce reciprocal activation. For example, astrocytes regulate the morphology, differentiation, and activation state of microglia (Streit et al., 1999; Rocha et al., 2012). Reactive microglial cells during LPS-induced systemic inflammation produce TNF- $\alpha, \mathrm{C} 1 \mathrm{q}$ and IL- $1 \alpha$, which activate astrocytes and induce the expression of neurotoxins from reactive astrocytes (Liddelow et al., 2017).

Glial cell phagocytosis may play beneficial or deleterious roles in the brain when they are dysregulated. The phagocytic capacity of astrocytes and microglia may be necessary for the clearing of unnecessary synapses, synaptic debris and extracellular protein aggregates, thus maintaining brain homeostasis and preventing aberrant immune responses. In contrast, hyperactivation of phagocytic pathways, such as classical complement cascades and MERTK phagocytic pathways, can induce damage to live synapses during AD (Savage et al., 2015) and neurons during stroke (Neher et al., 2013), respectively.

Further studies would be necessary to reveal the exact molecular and cellular players of the phagocytic events in specific disease settings. This knowledge is crucial to the development of relevant therapeutics targets and strategies for each specific disease.

\section{ACKNOWLEDGMENTS}

The authors thank all members of Chung's laboratory for their helpful discussion. This work was supported by the National Research Foundation of Korea (NRF) grant funded by the Korean government (MSIP) (NRF-2016M3C7A1905391 and NRF-2016R1C1B3006969) (W.-S.C).

\section{REFERENCES}

Akiyama, H., Barger, S., Barnum, S., Bradt, B., Bauer, J., Cole, G. M., Cooper, N. R., Eikelenboom, P., Emmerling, M., Fiebich, B. L., Finch, C. E., Frautschy, S., Griffin, W. S., Hampel, H., Hull, M., Landreth, G., Lue, L., Mrak, R., Mackenzie, I. R., McGeer, P. L., O'Banion, M. K., Pachter, J., Pasinetti, G., Plata-Salaman, C., Rogers, J., Rydel, R., Shen, Y., Streit, W., Strohmeyer, R., Tooyoma, I., Van Muiswinkel, F. L., Veerhuis, R., Walker, D., Webster, S., Wegrzyniak, B., Wenk, G. and Wyss-Coray, T. (2000) Inflammation and Alzheimer's disease. Neurobiol. Aging 21, 383-421.

Allen, N. J. and Barres, B. A. (2005) Signaling between glia and neurons: focus on synaptic plasticity. Curr. Opin. Neurobiol. 15, 542548.

Allen, N. J., Bennett, M. L., Foo, L. C., Wang, G. X., Chakraborty, C., Smith, S. J. and Barres, B. A. (2012) Astrocyte glypicans 4 and 6 
promote formation of excitatory synapses via GluA1 AMPA receptors. Nature 486, 410-414.

Araque, A., Sanzgiri, R. P., Parpura, V. and Haydon, P. G. (1999) Astrocyte-induced modulation of synaptic transmission. Can. J. Physiol. Pharmacol. 77, 699-706.

Austin, S. A., Floden, A. M., Murphy, E. J. and Combs, C. K. (2006) $\alpha$-synuclein expression modulates microglial activation phenotype. J. Neurosci. 26, 10558-10563.

Bellesi, M., de Vivo, L., Chini, M., Gilli, F., Tononi, G. and Cirelli, C. (2017) Sleep loss promotes astrocytic phagocytosis and microglial activation in mouse cerebral cortex. J. Neurosci. 37, 5263-5273.

Benkler, C., Ben-Zur, T., Barhum, Y. and Offen, D. (2013) Altered astrocytic response to activation in SOD1(G93A) mice and its implications on amyotrophic lateral sclerosis pathogenesis. Glia 61, 312-326.

Bolmont, T., Haiss, F., Eicke, D., Radde, R., Mathis, C. A., Klunk, W. E., Kohsaka, S., Jucker, M. and Calhoun, M. E. (2008) Dynamics of the microglial/amyloid interaction indicate a role in plaque maintenance. J Neurosci. 28, 4283-4292.

Cahoy, J. D., Emery, B., Kaushal, A., Foo, L. C., Zamanian, J. L., Christopherson, K. S., Xing, Y., Lubischer, J. L., Krieg, P. A., Krupenko, S. A., Thompson, W. J. and Barres, B. A. (2008) A transcriptome database for astrocytes, neurons, and oligodendrocytes: a new resource for understanding brain development and function. J. Neurosci. 28, 264-278.

Chen, K., Iribarren, P., Hu, J., Chen, J., Gong, W., Cho, E. H., Lockett S., Dunlop, N. M. and Wang, J. M. (2006) Activation of Toll-like receptor 2 on microglia promotes cell uptake of Alzheimer diseaseassociated amyloid $\beta$ peptide. J. Biol. Chem. 281, 3651-3659.

Cho, K. J., Cheon, S. Y. and Kim, G. W. (2016) Apoptosis signal-regulating kinase 1 mediates striatal degeneration via the regulation of C1q. Sci. Rep. 6, 18840.

Chung, W. S. and Barres, B. A. (2012) The role of glial cells in synapse elimination. Curr. Opin. Neurobiol. 22, 438-445.

Chung, W. S., Clarke, L. E., Wang, G. X., Stafford, B. K., Sher, A., Chakraborty, C., Joung, J., Foo, L. C., Thompson, A., Chen, C., Smith, S. J. and Barres, B. A. (2013) Astrocytes mediate synapse elimination through MEGF10 and MERTK pathways. Nature 504, 394-400.

Chung, W. S., Verghese, P. B., Chakraborty, C., Joung, J., Hyman, B. T., Ulrich, J. D., Holtzman, D. M. and Barres, B. A. (2016) Novel allele-dependent role for APOE in controlling the rate of synapse pruning by astrocytes. Proc. Natl. Acad. Sci. U.S.A. 113, 1018610191.

Clarke, L. E. and Barres, B. A. (2013) Emerging roles of astrocytes in neural circuit development. Nat. Rev. Neurosci. 14, 311-321.

Clement, A. M., Nguyen, M. D., Roberts, E. A., Garcia, M. L., Boillee, S., Rule, M., McMahon, A. P., Doucette, W., Siwek, D., Ferrante, R. J., Brown, R. H., Jr., Julien, J. P., Goldstein, L. S. and Cleveland, D. W. (2003) Wild-type nonneuronal cells extend survival of SOD1 mutant motor neurons in ALS mice. Science 302, 113-117.

Cuyvers, E., Bettens, K., Philtjens, S., Van Langenhove, T., Gijselinck, I., van der Zee, J., Engelborghs, S., Vandenbulcke, M., Van Dongen, J., Geerts, N., Maes, G., Mattheijssens, M., Peeters, K., Cras, P., Vandenberghe, R., De Deyn, P. P., Van Broeckhoven, C., Cruts, M. and Sleegers, K. (2014) Investigating the role of rare heterozygous TREM2 variants in Alzheimer's disease and frontotemporal dementia. Neurobiol. Aging 35, 726.e11-726.e19.

Depboylu, C., Schafer, M. K., Arias-Carrion, O., Oertel, W. H., Weihe, E. and Hoglinger, G. U. (2011) Possible involvement of complement factor $\mathrm{C} 1 \mathrm{q}$ in the clearance of extracellular neuromelanin from the substantia nigra in Parkinson disease. J. Neuropathol. Exp. Neurol. 70, 125-132.

Diniz, L. P., Matias, I. C., Garcia, M. N. and Gomes, F. C. (2014) Astrocytic control of neural circuit formation: highlights on TGF- $\beta$ signaling. Neurochem. Int. 78, 18-27.

Dong, J. H., Ying, G. X. and Zhou, C. F. (2004) Entorhinal deafferentation induces the expression of profilin mRNA in the reactive microglial cells in the hippocampus. Glia 47, 102-108.

Fraser, D. A., Pisalyaput, K. and Tenner, A. J. (2010) C1q enhances microglial clearance of apoptotic neurons and neuronal blebs, and modulates subsequent inflammatory cytokine production. J. Neu- rochem. 112, 733-743.

Fricker, M., Neher, J. J., Zhao, J. W., Thery, C., Tolkovsky, A. M. and Brown, G. C. (2012) MFG-E8 mediates primary phagocytosis of viable neurons during neuroinflammation. J. Neurosci. 32, 26572666.

Fu, R., Shen, Q., Xu, P., Luo, J. J. and Tang, Y. (2014) Phagocytosis of microglia in the central nervous system diseases. Mol. Neurobiol. 49, 1422-1434.

Gasque, P. (2004) Complement: a unique innate immune sensor for danger signals. Mol. Immunol. 41, 1089-1098.

Ghosh, R. and Tabrizi, S. J. (2015) Clinical aspects of huntington's disease. Curr. Top. Behav. Neurosci. 22, 3-31.

Gong, Y. H. and Elliott, J. L. (2000) Metallothionein expression is altered in a transgenic murine model of familial amyotrophic lateral sclerosis. Exp. Neurol. 162, 27-36.

Hanke, M. L. and Kielian, T. (2011) Toll-like receptors in health and disease in the brain: mechanisms and therapeutic potential. Clin Sci (Lond). 121, 367-387.

Hardiman, O., van den Berg, L. H. and Kiernan, M. C. (2011) Clinical diagnosis and management of amyotrophic lateral sclerosis. Nat. Rev. Neurol. 7, 639-649

Hayakawa, K., Esposito, E., Wang, X., Terasaki, Y., Liu, Y., Xing, C., Ji, X. and Lo, E. H. (2016) Transfer of mitochondria from astrocytes to neurons after stroke. Nature 535, 551-555.

Hong, S., Beja-Glasser, V. F., Nfonoyim, B. M., Frouin, A., Li, S., Ramakrishnan, S., Merry, K. M., Shi, Q., Rosenthal, A., Barres, B. A., Lemere, C. A., Selkoe, D. J. and Stevens, B. (2016) Complement and microglia mediate early synapse loss in Alzheimer mouse models. Science 352, 712-716.

Huang, B., Wei, W., Wang, G., Gaertig, M. A., Feng, Y., Wang, W., $\mathrm{Li}, \mathrm{X}$. J. and Li, S. (2015) Mutant huntingtin downregulates myelin regulatory factor-mediated myelin gene expression and affects mature oligodendrocytes. Neuron 85, 1212-1226.

Jana, M., Palencia, C. A. and Pahan, K. (2008) Fibrillar amyloid- $\beta$ peptides activate microglia via TLR2: implications for Alzheimer's disease. J. Immunol. 181, 7254-7262.

Jansen, A. H., van Hal, M., Op den Kelder, I. C., Meier, R. T., de Ruiter, A. A., Schut, M. H., Smith, D. L., Grit, C., Brouwer, N., Kamphuis, W., Boddeke, H. W., den Dunnen, W. F., van Roon, W. M., Bates, G. P., Hol, E. M. and Reits, E. A. (2017) Frequency of nuclear mutant huntingtin inclusion formation in neurons and glia is cell-typespecific. Glia 65, 50-61.

Jiang, R., Diaz-Castro, B., Looger, L. L. and Khakh, B. S. (2016) Dysfunctional calcium and glutamate signaling in striatal astrocytes from huntington's disease model mice. J. Neurosci. 36, 3453-3470.

Jones, R. S., Minogue, A. M., Connor, T. J. and Lynch, M. A. (2013) Amyloid- $\beta$-induced astrocytic phagocytosis is mediated by CD36, CD47 and RAGE. J. Neuroimmune Pharmacol. 8, 301-311.

Keren-Shaul, H., Spinrad, A., Weiner, A., Matcovitch-Natan, O., DvirSzternfeld, R., Ulland, T. K., David, E., Baruch, K., Lara-Astaiso, D., Toth, B., Itzkovitz, S., Colonna, M., Schwartz, M. and Amit, I. (2017) A unique microglia type associated with restricting development of Alzheimer's disease. Cell 169, 1276-1290.e17.

Kim, J. G., Moon, M. Y., Kim, H. J., Li, Y., Song, D. K., Kim, J. S., Lee, J. Y., Kim, J., Kim, S. C. and Park, J. B. (2012) Ras-related GTPases Rap1 and RhoA collectively induce the phagocytosis of serum-opsonized zymosan particles in macrophages. J. Biol. Chem. 287, 5145-5155.

Klegeris, A., Pelech, S., Giasson, B. I., Maguire, J., Zhang, H., McGeer, E. G. and McGeer, P. L. (2008) $\alpha$-synuclein activates stress signaling protein kinases in THP-1 cells and microglia. Neurobiol. Aging 29, 739-752.

Lasiene, J. and Yamanaka, K. (2011) Glial cells in amyotrophic lateral sclerosis. Neurol. Res. Int. 2011, 718987.

Lee, C. Y. and Landreth, G. E. (2010) The role of microglia in amyloid clearance from the AD brain. J Neural Transm (Vienna). 117, 949960.

Lee, Y. I., Li, Y., Mikesh, M., Smith, I., Nave, K. A., Schwab, M. H. and Thompson, W. J. (2016) Neuregulin1 displayed on motor axons regulates terminal Schwann cell-mediated synapse elimination at developing neuromuscular junctions. Proc. Natl. Acad. Sci. U.S.A. 113, E479-E487. 
Lee, Y. J., Han, S. B., Nam, S. Y., Oh, K. W. and Hong, J. T. (2010) Inflammation and Alzheimer's disease. Arch. Pharm. Res. 33, 15391556.

Lees, A. J., Hardy, J. and Revesz, T. (2009) Parkinson's disease. Lancet 373, 2055-2066.

Liddelow, S. A., Guttenplan, K. A., Clarke, L. E., Bennett, F. C., Bohlen, C. J., Schirmer, L., Bennett, M. L., Munch, A. E., Chung, W. S., Peterson, T. C., Wilton, D. K., Frouin, A., Napier, B. A., Panicker N., Kumar, M., Buckwalter, M. S., Rowitch, D. H., Dawson, V. L., Dawson, T. M., Stevens, B. and Barres, B. A. (2017) Neurotoxic reactive astrocytes are induced by activated microglia. Nature $\mathbf{5 4 1}$ 481-487.

Liu, S., Liu, Y., Hao, W., Wolf, L., Kiliaan, A. J., Penke, B., Rube, C. E., Walter, J., Heneka, M. T., Hartmann,T., Menger, M. D. and Fassbender, K. (2012) TLR2 is a primary receptor for Alzheimer's amyloid $\beta$ peptide to trigger neuroinflammatory activation. J. Immunol. 188, 1098-1107.

Lopez-Murcia, F. J., Terni, B. and Llobet, A. (2015) SPARC triggers a cell-autonomous program of synapse elimination. Proc. Natl. Acad. Sci. U.S.A. 112, 13366-13371.

Matarin, M., Salih, D. A., Yasvoina, M., Cummings, D. M., Guelfi, S., Liu, W., Nahaboo Solim, M. A., Moens, T. G., Paublete, R. M., Ali, S. S., Perona, M., Desai, R., Smith, K. J., Latcham, J., Fulleylove, M., Richardson, J. C., Hardy, J. and Edwards, F. A. (2015) A genome-wide gene-expression analysis and database in transgenic mice during development of amyloid or tau pathology. Cell Rep. 10, 633-644.

McGeer, P. L. and McGeer, E. G. (2013) The amyloid cascade-inflammatory hypothesis of Alzheimer disease: implications for therapy. Acta Neuropathol. 126, 479-497.

Meyer-Luehmann, M., Spires-Jones, T. L., Prada, C., Garcia-Alloza, M., de Calignon, A., Rozkalne, A., Koenigsknecht-Talboo, J. Holtzman, D. M., Bacskai, B. J. and Hyman, B. T. (2008) Rapid appearance and local toxicity of amyloid- $\beta$ plaques in a mouse model of Alzheimer's disease. Nature 451, 720-724.

Michelakakis, H., Xiromerisiou, G., Dardiotis, E., Bozi, M., Vassilatis, D., Kountra, P. M., Patramani, G., Moraitou, M., Papadimitriou, D. Stamboulis, E., Stefanis, L., Zintzaras, E. and Hadjigeorgiou, G. M. (2012) Evidence of an association between the scavenger receptor class B member 2 gene and Parkinson's disease. Mov. Disord. 27, 400-405.

Neher, J. J., Emmrich, J. V., Fricker, M., Mander, P. K., Thery, C. and Brown, G. C. (2013) Phagocytosis executes delayed neuronal death after focal brain ischemia. Proc. Natl. Acad. Sci. U.S.A. 110 E4098-E4107.

Nimmerjahn, A., Kirchhoff, F. and Helmchen, F. (2005) Resting microglial cells are highly dynamic surveillants of brain parenchyma in vivo. Science 308, 1314-1318.

Noda, M. and Suzumura, A. (2012) Sweepers in the CNS: Microglial migration and phagocytosis in the Alzheimer disease pathogenesis. Int. J. Alzheimers Dis. 2012, 891087.

Olson, J. K. and Miller, S. D. (2004) Microglia initiate central nervous system innate and adaptive immune responses through multiple TLRs. J. Immunol. 173, 3916-3924.

Painter, M. M., Atagi, Y., Liu, C. C., Rademakers, R., Xu, H., Fryer, J. D. and Bu, G. (2015) TREM2 in CNS homeostasis and neurodegenerative disease. Mol. Neurodegener. 10, 43.

Paolicelli, R. C. and Gross, C. T. (2011) Microglia in development: linking brain wiring to brain environment. Neuron Glia Biol. 7, 77-83.

Park, J. Y., Paik, S. R., Jou, I. and Park, S. M. (2008) Microglial phagocytosis is enhanced by monomeric alpha-synuclein, not aggregated alpha-synuclein: implications for Parkinson's disease. Glia 56 , 1215-1223.

Pearce, M. M., Spartz, E. J., Hong, W., Luo, L. and Kopito, R. R. (2015) Prion-like transmission of neuronal huntingtin aggregates to phagocytic glia in the Drosophila brain. Nat. Commun. 6, 6768

Phatnani, H. and Maniatis, T. (2015) Astrocytes in neurodegenerative disease. Cold Spring Harb Perspect Biol. 7, 1-17

Philips, T. and Robberecht, W. (2011) Neuroinflammation in amyotrophic lateral sclerosis: role of glial activation in motor neuron disease. Lancet Neurol. 10, 253-263.

Pihlaja, R., Koistinaho, J., Malm, T., Sikkila, H., Vainio, S. and Kois- tinaho, M. (2008) Transplanted astrocytes internalize deposited $\beta$-amyloid peptides in a transgenic mouse model of Alzheimer's disease. Glia 56, 154-163.

Pomilio, C., Pavia, P., Gorojod, R. M., Vinuesa, A., Alaimo, A., Galvan, V., Kotler, M. L., Beauquis, J. and Saravia, F. (2016) Glial alterations from early to late stages in a model of Alzheimer's disease: Evidence of autophagy involvement in $A \beta$ internalization. Hippocampus 26, 194-210.

Purice, M. D., Speese, S. D. and Logan, M. A. (2016) Delayed glial clearance of degenerating axons in aged Drosophila is due to reduced PI3K/Draper activity. Nat. Commun. 7, 12871

Radford, R. A., Morsch, M., Rayner, S. L., Cole, N. J., Pountney, D. L. and Chung, R. S. (2015) The established and emerging roles of astrocytes and microglia in amyotrophic lateral sclerosis and frontotemporal dementia. Front Cell Neurosci. 9, 414.

Rocha, S. M., Cristovao, A. C., Campos, F. L., Fonseca, C. P. and Baltazar, G. (2012) Astrocyte-derived GDNF is a potent inhibitor of microglial activation. Neurobiol. Dis. 47, 407-415.

Rojanathammanee, L., Murphy, E. J. and Combs, C. K. (2011) Expression of mutant $\alpha$-synuclein modulates microglial phenotype in vitro. J. Neuroinflammation $\mathbf{8}, 44$

Salminen, A., Ojala, J., Kauppinen, A., Kaarniranta, K. and Suuronen, T. (2009) Inflammation in Alzheimer's disease: amyloid- $\beta$ oligomers trigger innate immunity defence via pattern recognition receptors. Prog. Neurobiol. 87, 181-194.

Savage, J. C., Jay, T., Goduni, E., Quigley, C., Mariani, M. M., Malm, T., Ransohoff, R. M., Lamb, B. T. and Landreth, G. E. (2015) Nuclear receptors license phagocytosis by trem2+ myeloid cells in mouse models of Alzheimer's disease. J. Neurosci. 35, 6532-6543.

Schafer, D. P., Lehrman, E. K., Kautzman, A. G., Koyama, R., MardinIy, A. R., Yamasaki, R., Ransohoff, R. M., Greenberg, M. E., Barres, B. A. and Stevens, B. (2012) Microglia sculpt postnatal neural circuits in an activity and complement-dependent manner. Neuron 74, 691-705.

Selkoe, D. J. and Hardy, J. (2016) The amyloid hypothesis of Alzheimer's disease at 25 years. EMBO Mol Med. 8, 595-608.

Shin, J. Y., Fang, Z. H., Yu, Z. X., Wang, C. E., Li, S. H. and Li, X. J. (2005) Expression of mutant huntingtin in glial cells contributes to neuronal excitotoxicity. J. Cell Biol. 171, 1001-1012.

Sofroniew, M. V. (2015) Astrocyte barriers to neurotoxic inflammation. Nat. Rev. Neurosci. 16, 249-263.

Sofroniew, M. V. and Vinters, H. V. (2010) Astrocytes: biology and pathology. Acta Neuropathol. 119, 7-35.

Sollvander, S., Nikitidou, E., Brolin, R., Soderberg, L., Sehlin, D., Lannfelt, L. and Erlandsson, A. (2016) Accumulation of amyloid- $\beta$ by astrocytes result in enlarged endosomes and microvesicle-induced apoptosis of neurons. Mol. Neurodegener. 11, 38.

Song, J. W., Misgeld, T., Kang, H., Knecht, S., Lu, J., Cao, Y., Cotman, S. L., Bishop, D. L. and Lichtman, J. W. (2008) Lysosomal activity associated with developmental axon pruning. J. Neurosci. 28 , 8993-9001.

Stephan, A. H., Madison, D. V., Mateos, J. M., Fraser, D. A., Lovelett, E. A., Coutellier, L., Kim, L., Tsai, H. H., Huang, E. J., Rowitch, D. H., Berns, D. S., Tenner, A. J., Shamloo, M. and Barres, B. A. (2013) A dramatic increase of C1q protein in the CNS during normal aging. J. Neurosci. 33, 13460-13474.

Stevens, B., Allen, N. J., Vazquez, L. E., Howell, G. R., Christopherson, K. S., Nouri, N., Micheva, K. D., Mehalow, A. K., Huberman, A. D., Stafford, B., Sher, A., Litke, A. M., Lambris, J. D., Smith, S. J., John, S. W. and Barres, B. A. (2007) The classical complement cascade mediates CNS synapse elimination. Cell 131, 1164-1178.

Streit, W. J., Walter, S. A. and Pennell, N. A. (1999) Reactive microgliosis. Prog. Neurobiol. 57, 563-581.

Suh, E. C., Jung, Y. J., Kim, Y. A., Park, E. M., Lee, S. J. and Lee, K. E. (2013) Knockout of Toll-like receptor 2 attenuates A $325-35$-induced neurotoxicity in organotypic hippocampal slice cultures. Neurochem. Int. 63, 818-825.

Tahara, K., Kim, H. D., Jin, J. J., Maxwell, J. A., Li, L. and Fukuchi, K. (2006) Role of toll-like receptor signalling in $A \beta$ uptake and clearance. Brain 129, 3006-3019.

Tang, S. C., Arumugam, T. V., Xu, X., Cheng, A., Mughal, M. R., Jo, D. G., Lathia, J. D., Siler, D. A., Chigurupati, S., Ouyang, X., Mag- 
nus, T., Camandola, S. and Mattson, M. P. (2007) Pivotal role for neuronal Toll-like receptors in ischemic brain injury and functional deficits. Proc. Natl. Acad. Sci. U.S.A. 104, 13798-13803.

Tasdemir-Yilmaz, O. E. and Freeman, M. R. (2014) Astrocytes engage unique molecular programs to engulf pruned neuronal debris from distinct subsets of neurons. Genes Dev. 28, 20-33.

Terni, B., Lopez-Murcia, F. J. and Llobet, A. (2017) Role of neuron-glia interactions in developmental synapse elimination. Brain Res. Bull. 129, 74-81.

Tong, X., Ao, Y., Faas, G. C., Nwaobi, S. E., Xu, J., Haustein, M. D. Anderson, M. A., Mody, I., Olsen, M. L., Sofroniew, M. V. and Khakh, B. S. (2014) Astrocyte Kir4.1 ion channel deficits contribute to neuronal dysfunction in Huntington's disease model mice. Nat. Neurosci. 17, 694-703.

Turner, M. R., Cagnin, A., Turkheimer, F. E., Miller, C. C., Shaw, C. E., Brooks, D. J., Leigh, P. N. and Banati, R. B. (2004) Evidence of widespread cerebral microglial activation in amyotrophic latera sclerosis: an [11C](R)-PK11195 positron emission tomography study. Neurobiol. Dis. 15, 601-609.

Ulland, T. K., Song, W. M., Huang, S. C., Ulrich, J. D., Sergushichev, A., Beatty, W. L., Loboda, A. A., Zhou, Y., Cairns, N. J., Kambal, A., Loginicheva, E., Gilfillan, S., Cella, M., Virgin, H. W., Unanue, E. R., Wang, Y., Artyomov, M. N., Holtzman, D. M. and Colonna, M. (2017) TREM2 maintains microglial metabolic fitness in Alzheimer's disease. Cell 170, 649-663.e13.

Ulrich, J. D. and Holtzman, D. M. (2016) TREM2 function in Alzheimer's disease and neurodegeneration. ACS Chem. Neurosci. 7 420-427.

Wang, Y., Cella, M., Mallinson, K., Ulrich, J. D., Young, K. L., Robinette, M. L., Gilfillan, S., Krishnan, G. M., Sudhakar, S., Zinselmeyer, B. H., Holtzman, D. M., Cirrito, J. R. and Colonna, M. (2015) TREM2 lipid sensing sustains the microglial response in an Alzheimer's disease model. Cell 160, 1061-1071.

Weydt, P., Yuen, E. C., Ransom, B. R. and Moller, T. (2004) Increased cytotoxic potential of microglia from ALS-transgenic mice. Glia $\mathbf{4 8}$, 179-182.

Wyss-Coray, T., Loike, J. D., Brionne, T. C., Lu, E., Anankov, R., Yan, F., Silverstein, S. C. and Husemann, J. (2003) Adult mouse astrocytes degrade amyloid- $\beta$ in vitro and in situ. Nat. Med. 9, 453-457.

Yamanaka, K., Chun, S. J., Boillee, S., Fujimori-Tonou, N., Yamashita, H., Gutmann, D. H., Takahashi, R., Misawa, H. and Cleveland, D. W. (2008) Astrocytes as determinants of disease progression in inherited amyotrophic lateral sclerosis. Nat. Neurosci. 11, 251-253.

Yang, J., Yang, H., Liu, Y., Li, X., Qin, L., Lou, H., Duan, S. and Wang, H. (2016a) Astrocytes contribute to synapse elimination via type 2 inositol 1,4,5-trisphosphate receptor-dependent release of ATP. Elife 5, e15043.

Yang, L., Liu, C. C., Zheng, H., Kanekiyo, T., Atagi, Y., Jia, L., Wang, D., N'Songo, A., Can, D., Xu, H., Chen, X. F. and Bu, G. (2016b) LRP1 modulates the microglial immune response via regulation of JNK and NF-KB signaling pathways. J. Neuroinflammation 13, 304

Zhang, B., Tian, M., Zheng, H., Zhen, Y., Yue, Y., Li, T., Li, S., Marcantonio, E. R. and Xie, Z. (2013) Effects of anesthetic isoflurane and desflurane on human cerebrospinal fluid $A \beta$ and t level. Anesthesiology 119, 52-60.

Zhang, Y., Chen, K., Sloan, S. A., Bennett, M. L., Scholze, A. R., O’Keeffe, S., Phatnani, H. P., Guarnieri, P., Caneda, C., Ruderisch, N., Deng, S., Liddelow, S. A., Zhang, C., Daneman, R., Maniatis, T., Barres, B. A. and Wu, J. Q. (2014) An RNA-sequencing transcriptome and splicing database of glia, neurons, and vascular cells of the cerebral cortex. J. Neurosci. 34, 11929-11947. 